\title{
The voltage dip and doubly fed induction generator with considering uncertainty conditions
}

\author{
Zahra Rafiee, Mansour Rafiee, Mohammad Reza Aghamohammadi
}

Faculty of Electrical Engineering, Shahid Beheshti University, Daneshju Blvd, Velenjak, Tehran, 1983969411, Iran

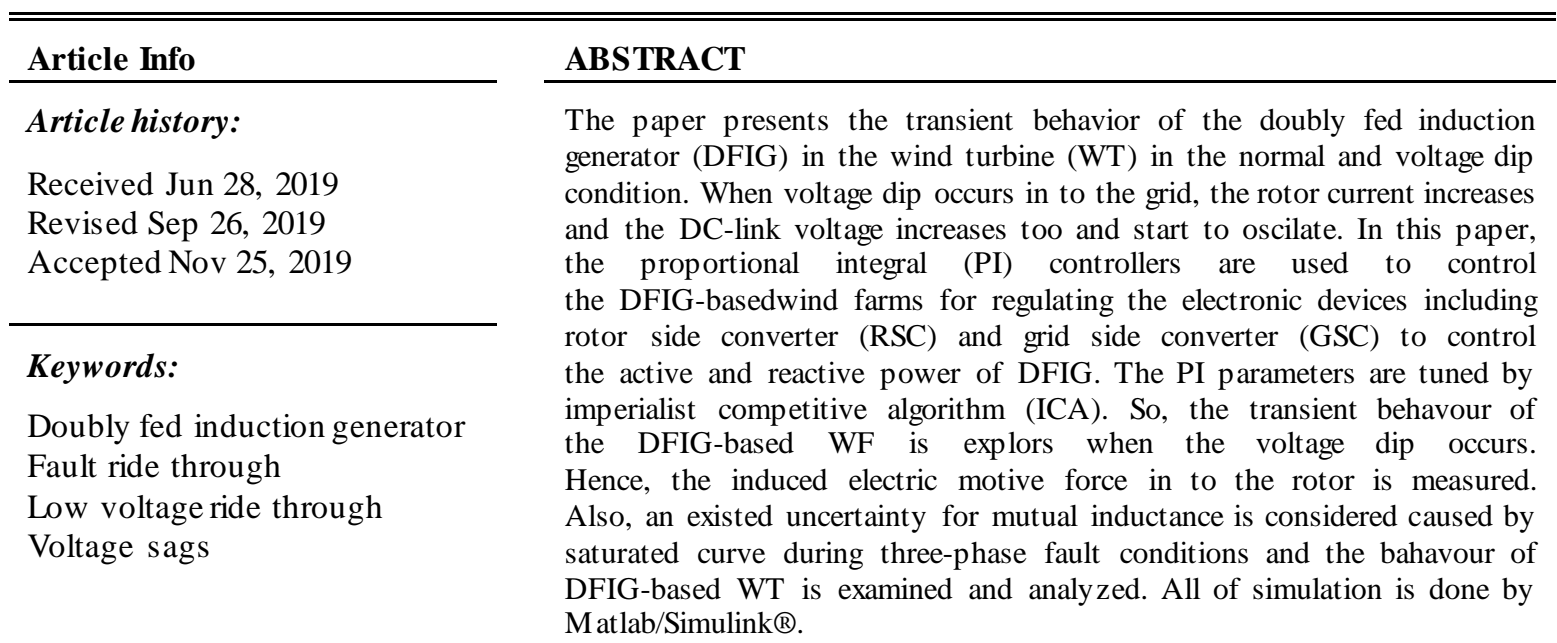

This is an open access article under the $\underline{C C B Y-S A}$ license.

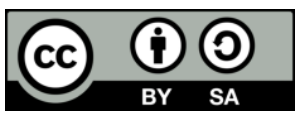

\section{Corresponding Author:}

Zahra Rafiee,

Faculty of Electrical Engineering,

Shahid Beheshti University,

Daneshju Blu, Velenjak, Tehran, 1983969411, Iran.

Email: z_rafiee@sbu.ac.ir

\section{INTRODUCTION}

Wind energy is growing fast for generating electricity because it is an important source of renewable energy resources [1]. With increasing penetration level of wind energy into the grid, wind turbine should remain connected to the grid to support the stability during various grid fault scenarios based on grid codes' requirement [2]. The ability of the wind turbines to stay connected to the network during the voltage dips is called the low voltage ride through (LVRT) [3]. DFIG is one of the important generator used in the wind farmbut it is very sensitive to the grid disturbances [4].

When a voltage dip occurs in the DFIG-based WT, two major issues are happened in the DFIG-based WT. The first one is the DC-link overvoltage, and the second one is rotor and stator over-current. Both of them can be supplied the excessive energy which cannot be transmitted into the electrical grid during voltage dip. The power electronics converters in the DFIG-based WT can't undergo overcurrents and overvoltages because they have a relatively low power rating. Also, the DC-Link capacitor is damaged when the overvoltage occurs. Hence, studying the LVRT capability of the DFIG-based WT is very requirment [5]. For the purpose of transient analysis of the DFIG, the passive LVRT capability method has been developed. Therefore, dynamic modelling of the DFIG has been needed. Additionally, for transient stability enhancement, the LVRT is improved by a Demagnetization Current Controller [6]. 
Many of research activities have focused on the impact of the disturbances on the DFIG-based WT in the fault conditions. So, they have proposed using a DC chopper to smooth DC link overvoltage and a crowbar resistor to suppress rotor overcurrent as the first solution in VD conditions [7]. When a fault occurs the conventional crowbar causes the rotor of the DFIG becomes short circuit, as it is installed across the rotor terminals. Consequently, the rotor is blocked and the DFIG begins absorbing reactive power from the grid. But the new model of the crowbar resistance only limits the current during the fault using the power electronic devices and new methods of control [8]. Some researcers present devices which absorb DC link overvoltage $[9,10]$.

While the crowbar resistance and DC chopper are necessary for the protection systems, the usage of the energy storage system and the fault current limiters can increase the costs and decrease the system reliability [11]. Also, some researchers have designed more advanced control strategies for the RSC and the GSC [12], though some of these algorithms are too complicated and control parameters must choose precisely and properly. For example, in [13] has been proposed a control strategy to maximize the wind energy captured in a DFIG, at low to medium wind speeds. The robust nonlinear controller using the Hamiltonian controller in the presence of disturbances for the DFIG is proposed in [14]. To avoid dealing with the zero dynamic limitation brought by the bidirectional power flow through the RSC and the GSC in a DFIG, a new energy-based modeling and control scheme for the GSC is proposed in [15]. The other auxiliary hardware for LVRT enhancement such as a stator dynamic composite fault current limiter in the stator [16], a super capacitor energy storage system connected to the point of common coupling (PCC) [17], a bridge type fault current limiter connected to the PCC [18], a STATCOM connected to PCC [19], DC-link switchable resistive-type fault current limiter [20], a dynamic voltage restorer [21], a new stator-damping resistor unit and rotor current control [22], an active crowbar protection in the rotor [23], and etc. Moreover, using hardware strategies actually installs extra hardware in the DFIG and can increase the costs and may reduce the reliability of the system.

This paper presents effects a voltage dip event on the rotor and stator of the DFIG. Then, it proposes a very simple control strategy using PI controllers to regulate and drive the RSC and GSC. So, to achieve to decrease the rotor over current and DC link over voltage through the VD conditions, PI controllers' parameters, using the ICA are tunned and optimized. The uncertainty in DFIG parameters such as mutual inductance and saturated curve is also considered for DFIG in VD condition and the effects of it analyzed. This paper is organized as follows: in section II, the modelling of the DFIG-based WT is introduced. In section III, the transient behavour of DFIG in VD condition is examined. in section IV, the simulation results by MATLAB/SIMULINK@ are shown to validate the proposed method.

\section{DFIG-BASED WIND FARM MODEL}

It is necessary to examine the exchange of the active and reactive power between a DFIG-based wind farm and an electrical network using a precise model. The schematic diagram of a DFIG-based wind farm system connected to the grid is shown in Figure 1. The DFIG-based WT, including the doubly fed induction generator, Three-bladed wind turbine, the back-to-back converters (GSC and RSC), the drive train, and the control systems, are connected to the network through a three-phase transformer. The control system consists of three control parts including the WF control, the WT control, and the DFIGcontrol. The WT part controls the mechanical power of the wind turbine through the pitch angle and generates the reference value of the rotor speed of the DFIG based on the measured wind speed and the reference value for active power tuned by Transmission System' Operator (TSO) [24]. The DFIG control part, including the RSC and GSC controllers, and the voltage regulator for the DC-link control the active and reactive power of the DFIGusing the PI controllers. This study has used the DFIG-based wind farm connected to the infinite bus for explaining the transient behavior of the DFIG-based wind farm in a voltage sag event. The single line diagram of the test systemis shown in Figure 1. The parameters of the DFIG based WT are listed in Appendix.

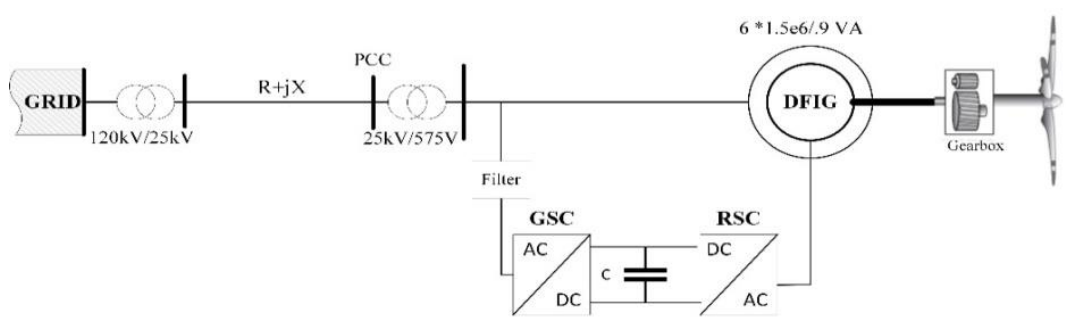

Figure 1. The single line diagram of the test system 


\section{THE TRANSIENT BEHAVIORS OF DFIG}

DFIG is highly sensitive to changes in its terminal voltage. Generally, when a disturbance occurs in the network causing a VD at the DFIG terminal, if the necessary actions are not taken, the following problems can arise:

- Stator flux fluctuations

- Increase in the electromotive force in the rotor winding

- Increase in the rotor current

- Increase in the DC link voltage

- Swing in torque and speed

In order to provide a better physical understanding of the DFIG behavior during a VD condition, some of the above phenomena are investigated analytically as follows.

\subsection{The increase in the electromotive force in the rotor winding}

In this section, the behavior of the stator flux fluctuation and the induced electromotive force in the rotor winding is investigated analytically and corresponding equations are derived for two cases including normal and VD conditions.

\subsubsection{Normal condition}

By reducing DFIG terminal voltage, the stator flux changes and large electromotive force (about 3 to 4 times the nominal value) is induced in the rotor winding. This phenomenon can be explained as follows. 1 and 2 show the relationship between fluxes, currents and voltages of the stator and rotor windings.

$$
\begin{aligned}
& \lambda_{s}=L_{s} i_{s}+L_{m} i_{r} \\
& \lambda_{r}=L_{m} i_{s}+L_{r} i_{r} \\
& u_{s}=R_{s} i_{s}+\frac{d \lambda_{s}}{d t} \\
& u_{r}=R_{r} i_{r}+\frac{d \lambda_{r}}{d t}
\end{aligned}
$$

Using (1), the stator current can be expressed as follows:

$$
i_{s}=\lambda_{s} / L_{s}-L_{m} i_{r} / L_{s}
$$

Substituting (5) in (2) gives the following for rotor flux:

$$
\begin{aligned}
& \lambda_{r}=L_{m}\left(\frac{1}{L_{s}} \lambda_{s}-\frac{L_{m}}{L_{s}} i_{r}\right)+L_{r} i_{r}=\frac{L_{m}}{L_{s}} \lambda_{s}+L_{r}\left(1-\frac{L_{m}^{2}}{L_{s} L_{r}}\right) i_{r} \\
& \lambda_{r}=L_{m} \lambda_{s} / L_{s}+\left(\sigma_{r} L_{r} i_{r}\right)
\end{aligned}
$$

where $\left(1-L_{m}^{2} /\left(L_{S} L_{r}\right)\right)$ is defined as rotor leakage coefficient $\left(\sigma_{r}\right)$. Derivative of (7) yields (8).

$$
\frac{d \lambda_{r}}{d t}=\frac{L_{m}}{L_{s}} \frac{d \lambda_{s}}{d t}+\left(\sigma_{r} L_{r}\right) \frac{d i_{r}}{d t}
$$

By expressing (4) in the stator reference frame, and substituting (8) into (4), it yields:

$$
u_{r}^{S}=R_{r} i_{r}^{S}+\frac{d \lambda_{r}^{S}}{d t}=\frac{L_{m}}{L_{S}} \frac{d \lambda_{s}^{S}}{d t}+\left(R_{r}+\sigma L_{r} \frac{d}{d t}\right) i_{r}^{s}
$$

In (9), the first term refers to the induced voltage in the rotor winding due to the stator flux fluctuations which is denoted as $E M F_{r}^{S}$ : 


$$
E M F_{r}^{S}=\frac{L_{m}}{L_{s}} \frac{d \lambda_{s}^{S}}{d t}
$$

By substituting the stator voltage phasor $u_{S}=V_{s} e^{j \omega_{e} t}$ in (3) and neglecting the stator resistance we obtain:

$$
V_{s} e^{j \omega_{e} t}=u_{S}=R_{S} i_{S}+d \lambda_{S} / d t \approx d \lambda_{S} / d t
$$

By expressing (11) in the stator reference frame, and integrating of stator voltage phas or it yields:

$$
\lambda_{s}^{s}=\int u_{s} d t=\int V_{s} e^{j \omega_{e} t} d t=V_{s} e^{j \omega_{e} t} / j \omega_{e}
$$

By expressing (12) in the rotor reference frame, the statorflux in the rotor winding can be derived as follows:

$$
\lambda_{s}^{r}=V_{s} e^{j \omega_{e} t} \times e^{-j \omega_{r} t} / j \omega_{e}=V_{s} e^{j\left(\omega_{e}-\omega_{r}\right) t} / j \omega_{e}=V_{s} e^{j\left(s \omega_{e}\right) t} / j \omega_{e}
$$

By expressing (10) in the rotor reference frame, it will yield the following:

$$
E M F_{r}^{r}=\frac{L_{m}}{L_{S}} \frac{d \lambda_{s}^{r}}{d t}=\frac{L_{m}}{L_{S}} \frac{d}{d t}\left(\frac{V_{s}}{j \omega_{e}} e^{j\left(s \omega_{e}\right) t}\right)=\frac{L_{m}}{L_{s}} s V_{s} e^{j s \omega_{e} t}=\frac{L_{m}}{L_{S}} s V_{s} e^{j \omega_{s} t}
$$

Generally, at normal conditions, slip (s) varies between -0.3 and +0.3 yielding a low value for $E M F_{r}^{r}$

\subsubsection{Voltage dip condition}

In this section, the effect of a symmetrical VD condition on the rotor induced EMF is investigated. For evaluating the changes in the stator flux due to a VD at the PCC, the rotor is assumed to be open-circuit and the impact of the rotor current on the stator flux is neglected. By combining (1) and 3 for stator flux and neglecting rotor current $\left(i_{r}=0\right)$ and representing stator voltage $u_{s}$ by phasor, (15) will be obtained:

$$
\frac{d}{d t} \lambda_{s}+\frac{R_{s}}{L_{s}} \lambda_{S}=u_{s}=V_{s}(1-g) e^{j \omega_{e} t}
$$

By integrating (15) in the stator reference frame,(16) will be obtained.

$$
\lambda_{s}^{s}=\frac{V_{s}(1-g)}{j \omega_{e}} e^{j \omega_{e} t}+\frac{V_{s} g}{j \omega_{e}} e^{-t / \tau_{s}}
$$

where $\tau_{s}=L_{S} / R_{S}$ is the time constant of the stator winding and $g$ refers to the VD percentage. The first and second terms of (16) represent the positive sequence and DC component of the stator flux respectively. The statorflux in the rotor reference frame can be expressed as follows:

$$
\lambda_{S}^{r}=\left(\frac{V_{S}(1-g)}{j \omega_{e}} e^{j \omega_{e} t}+\frac{V_{s} g}{j \omega_{e}} e^{-t / \tau_{s}}\right) \times e^{-j \omega_{r} t}=\frac{V_{S}(1-g)}{j \omega_{e}} e^{j\left(s \omega_{e}\right) t}+\frac{V_{s} g}{j \omega_{e}} e^{-j \omega_{r} t} \times e^{-t / \tau_{s}}
$$

When the voltage at the PCC decreases due to a symmetrical fault in the network, the induced electromotive force in the rotor reference frame $E M F_{r}^{r}$ is derived from (17):

$$
E M F_{r}^{r}=\frac{L_{m}}{L_{s}} \frac{d}{d t} \lambda_{s}^{r}=\frac{L_{m}}{L_{s}}\left[s V_{s}(1-g) e^{j\left(\omega_{e}-\omega_{r}\right) t}-\frac{V_{s} g}{j \omega_{e}}\left(\frac{1}{\tau_{s}}+j \omega_{r}\right) e^{-j \omega_{r} t} e^{-t / \tau_{s}}\right]
$$

By neglecting $1 / \tau_{S},(18)$ can be simplified as:

$$
E M F_{r}^{r}=L_{m}\left[s V_{s}(1-g) e^{j\left(\omega_{e}-\omega_{r}\right) t}-V_{s} g(1-s) e^{-j \omega_{r} t} e^{-t / \tau_{s}}\right] / L_{s}
$$


From (19), it can be seen that at the initial moments of the fault $(\mathrm{t}=0)$, the induced $\operatorname{EMF}_{r}^{r}(0)$ is relatively large due to the DC offset in the flux. For example, for s=-0.2 and $\mathrm{g}=1$, the value of the $\operatorname{EMF}_{r}^{r}(0)$ becomes $1.2 V_{s} L_{m} / L_{s}$ in the initial moments, which is 6 times the normal value. Also, (19) shows that the induced EMF depends on the speed of the generator, the amount of VD, and the stator voltage before VD. Therefore, the initial value of the induced EMF immediately after a VD can be evaluated as follows:

$$
E M F_{r}^{r}(0) \approx \frac{L_{m}}{L_{S}}\left[|s| V_{s}(1-g)+V_{s} g(1-s)\right]
$$

\subsection{Analytical analysis of the flux and induced EMF during VD}

In this section, by using analytical equations derived for DFIG, the variation of stator flux and induced EMF are illustrated. For this purpose, a $2.5 \mathrm{MW}, 690$ volts DFIG is used and by solving (17) and (18), the variation of the stator flux and induced EMF are obtained. In this study, at $\mathrm{t}=200 \mathrm{~ms}$, when the slip is -0.2 , a three-phase VD ( $g=0.9$ ) occurs. Figure 2(a) and 2(b) show the stator flux fluctuations in the stator and rotor reference frames respectively. Figure 2(c) shows the induced EMF variation in the rotor due to stator flux fluctuation. The variation of the induced EMF in the rotor at the initial moment of a VD event with respect to VD\% and slip is illustrated in Figure 2(d). As it can be seen, the maximum EMF is induced when $\mathrm{g}=1.0$ and $\mathrm{s}=-0.3$, which refers to a higher speed of DFIG.

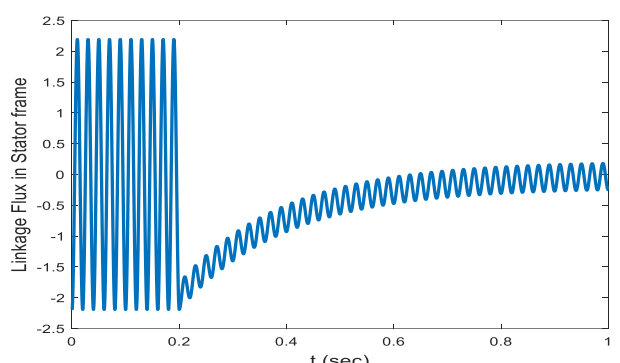

(a)

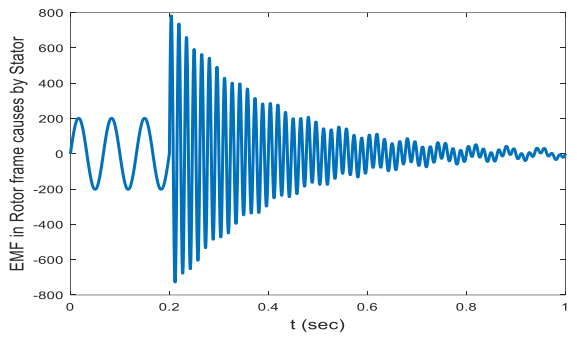

(c)

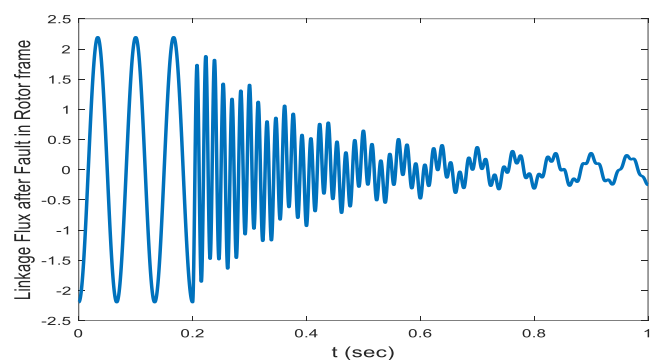

(b)

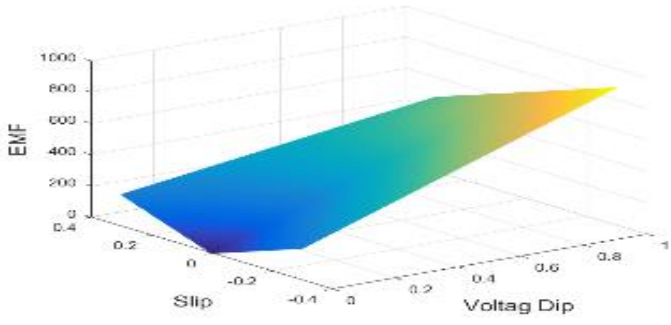

(d)

Figure 2. (a) Stator flux fluctuations in the stator reference frame, (b) Stator flux fluctuations in the rotor reference frame, (c) The inducted EMF in the rotor winding due to stator flux luctuation, and (d) The variation of the EMF at the initial moment of VD event with respect to slip and voltage dip

\section{THE PRINCIPLE OF PI CONTROL PROPOSED METHOD}

\subsection{Proposed control method for studying the the saturation curve}

In this approach, it has been used the six PI controllers for driving and controlling of the DFIG-based WF. PI controllers have set very simple, two PI contollers for RSC, 3 PI controllers for GSC and one PI controller for driving the speed of the rotor. Figure 3 shows the block diagram of the proposed control method for DFIG-based WT. Fot tunning the PI parameters the ICA has been used that it has been done in steady-state condition and transient behaviour $[25,26]$. The innovation used in this paper is the use of six PI controllers without any extra hardware strategy which causes to increase cost. Also, proposed control method is very simplicity and decreases the calculation content. 


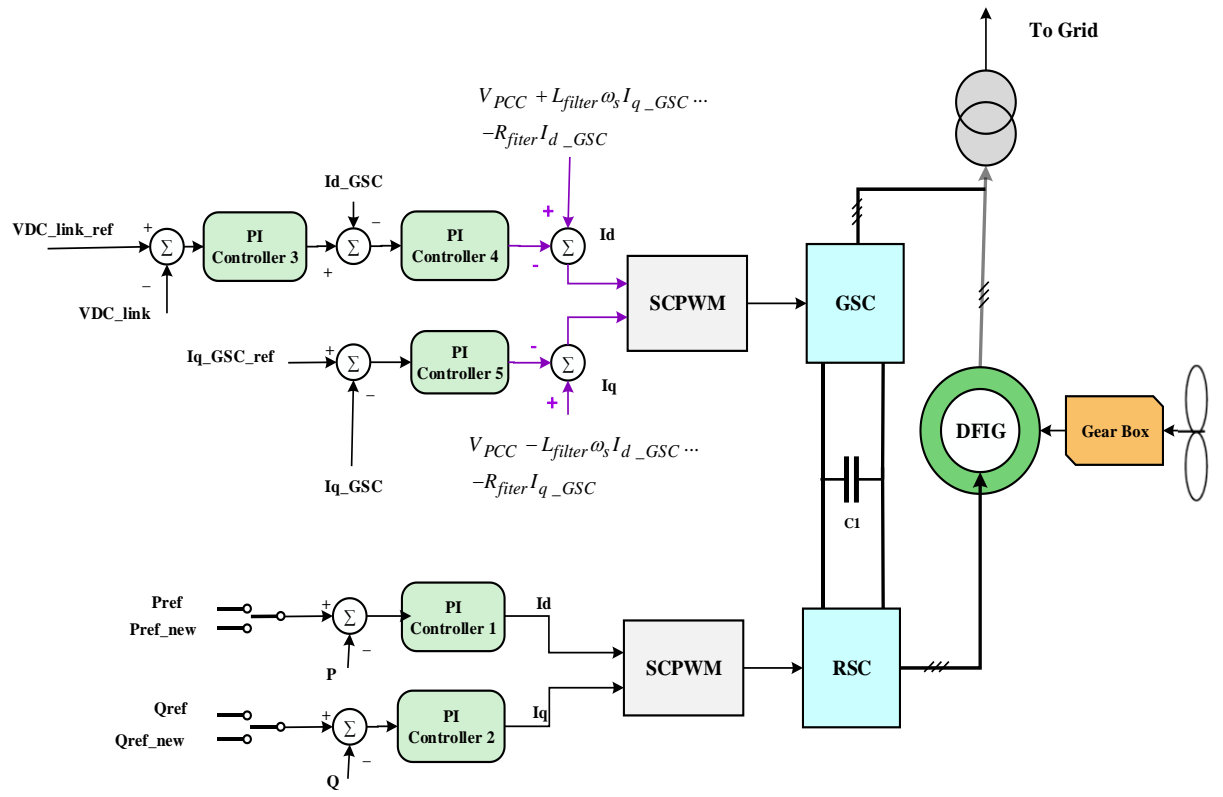

Figure 3. The proposed control method DFIG-based wind farm connected to infinite bus

\section{RESULTS AND DISCUSSIONS}

For finding the influences of the saturation curve of the DFIG, a three-phase fault occurs into the grid causing a voltage dip in PCC of the DFIG. Considered value for VD is 0.9 per unit and it takes 300 milliseconds and occurs in $t=0.5 \mathrm{~s}$. Finally, the DFIG response to VD condition has been examined using two scenarios including (a) saturation curve (WSC) and (d) without using saturation curve (WoSC) in which the mutual inductance equals to 2.9 p.u. Figure 4(a) presents the variation of the objective function in terms of the iteration and Figure 4(b) shows the saturation curve of DFIG of $\mathrm{Lm}$. In the steady state condition, according to saturation curve, $\mathrm{Lm}$ equals to 2.9 p.u but during $90 \% \mathrm{VD}$, it is equal to 3.7 p.u.

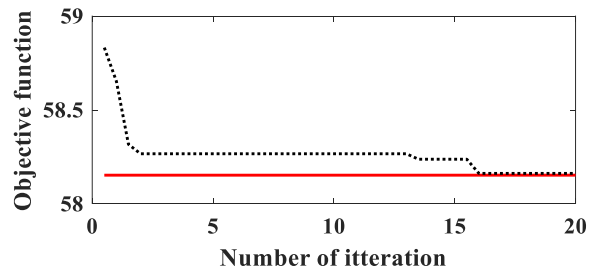

(a)

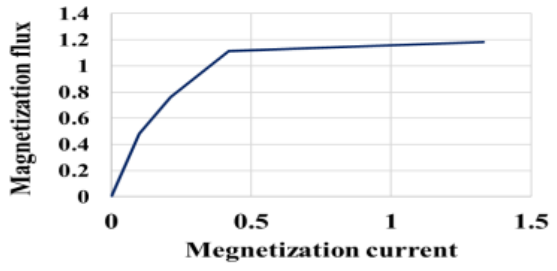

(b)

Figure 4. (a) Objective function curve, (b) saturation curve

Figure 5 shows the DFIG-based wind turbine response under 90\% symmetric three-phase VD. As depicted in Figures 5(a), when VD occurs the oscilation of active power is dis appeared after $0.625 \mathrm{~s}$ using WoSC and 0.67s using WSC. As shown in Figures 5(b), during VD, the oscilation of the reactive power of the DFIG is vanished after 0.69s using WoSC and 0.6s using WSC. As depicted in Figures 5(c), using WSC, the increase of the PCC voltage is equal to 0.6553 p.u and the oscilation is finished at $0.69 \mathrm{~s}$, while by using WoSC, the PCC voltage is 0.6875 p.u and the oscilation is finished at 0.563 p.u. The fluctuation of the q-axis of the rotor current in synchronous reference frame depicted in Figures 5(d) is vanished at 0.5625s using WoSC and 0.65s using WSC, but in these two scenarios, the d-axis of the rotor current does not have fluctuation when VD occurs. The fluctuation of the q-axis of the stator current in depicted in Figures 5(e) is vanished after $0.5625 \mathrm{~s}$ using WoSC and $0.625 \mathrm{~s}$ using WSC, but in these two scenarios, the d-axis of the rotor current has a low fluctuation when VD occurs. As can be seen in Figures 5(f), the machine speed does not have the sensitive differences in the mentioned scenarios.

Depending on the results, when using WSC, the fluctuations of the variables of the DFIG-based WT increase because when the VD occurs, on the basis of the saturation curve, the $\mathrm{Lm}$ varies and increases. 
The values of Lm creates an uncertainty when the VD happens. So, it needs to use the robust controllers in which the uncertainties such as saturation curve, wind speed, or variations of machine variables can not influence on them. In addition, with regard to the results in Figure 5(c), the $\mathrm{L}_{\mathrm{m}}$ value affects on the increase of voltage profile of the PCC during the VD condition and decreases it.
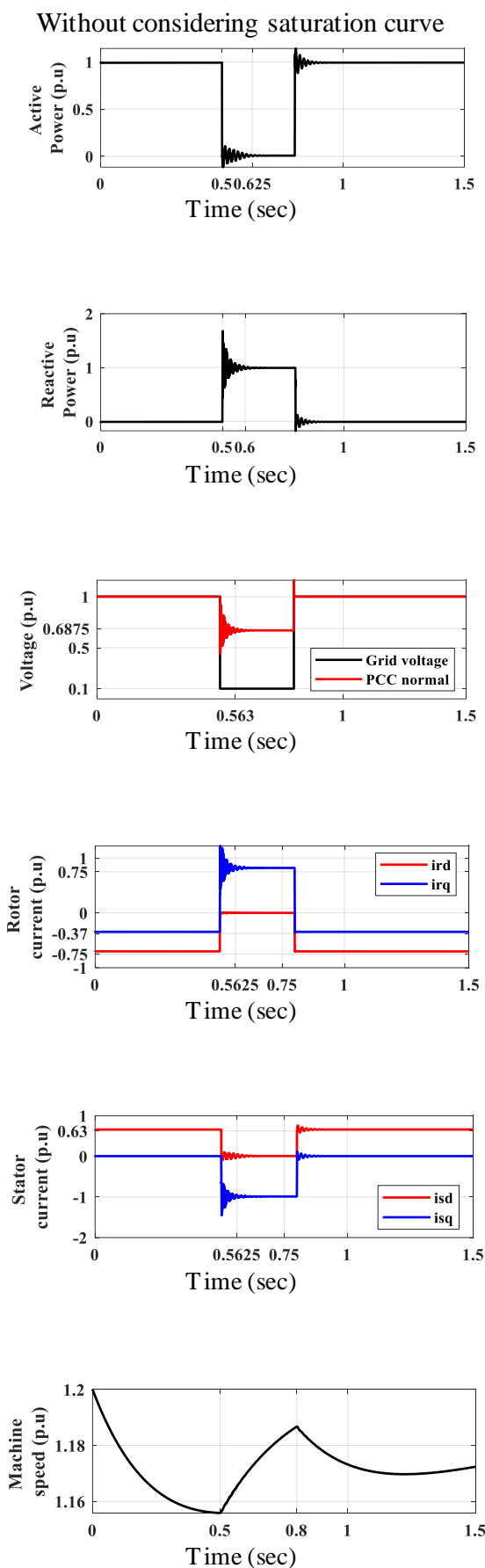

With considering saturation curve

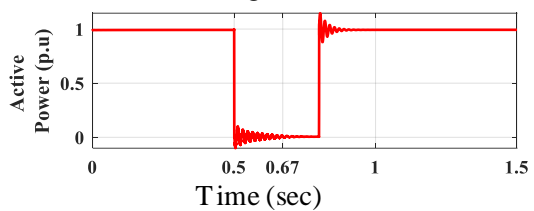

(a)

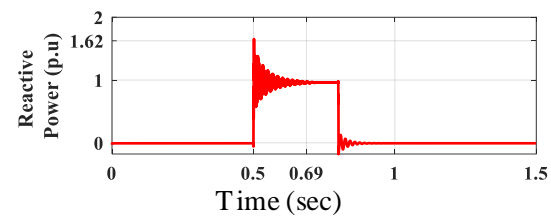

(b)

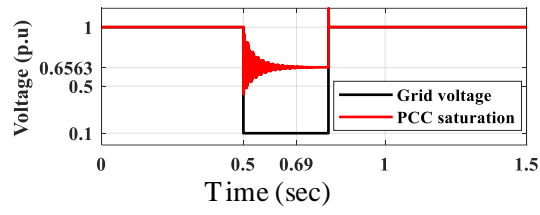

(c)

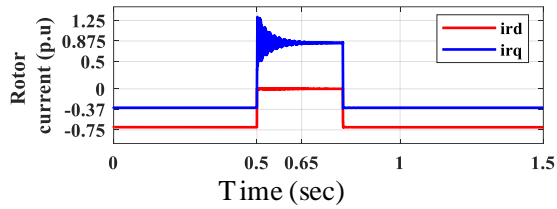

(d)

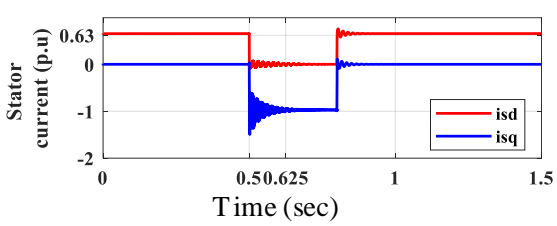

(e)

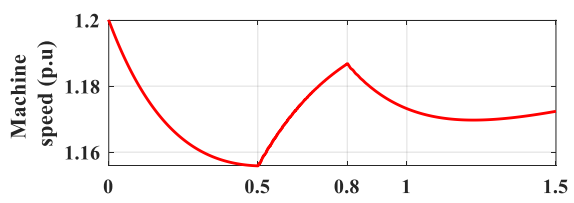

(f)

Figure 5. (a) The active power, (b) the reactive power, (c) the PCC voltage, (d) the $\mathrm{d}$ and q-axis rotor current,

(e) the $d$ and q-axis stator current, and (f) the machine speed of the DFIG without and with saturation cure under $90 \%$ VD condition

\section{CONCLUSIONS}

In this research, the transient behaviour of the DFIG under VD condition is examined. Depending on the results, when the slip of machine is maximum and the machine works on the su per-synchronous speed, 
the induced EMF is maximum. Also, with considering the uncertainty in the mutual inductance, us ing saturation curve, the variables of the DFIG in response to VD condition have more oscilitions. Also, under VD condition using saturation curve, the values of the voltage profile in the PCC decreases. So, it needs to use the robust controllers in which the uncertatinties such as saturation curve, wind speed, or variations of machine variables can not influence on the operation of the DFIG. This study has used the simple model of GSC and RSC including a gain whithout delay unit. This model is clearly sufficient to show the influence of saturation curve beacause the full model of GSC and RSC do not have effect on the mutual inductance.

\section{APPENDIX \\ DFIG-based wind farm parameters:}

Rated power $\mathrm{DFIG}=1.5 \mathrm{MW}$, stator voltage $=575 \mathrm{~V}$, magnetization inductance generator=2.9 pu, stator leakage inductance $=0.18 \mathrm{pu}$, rotor leakage inductance $=0.16 \mathrm{pu}$, rotor resistance $=0.016 \mathrm{pu}$, stator resistance $=0.023 \mathrm{pu}$, number of pair of poles $=3$, conversion ratio from stator to rotor: $575 / 1975$, frequency $=60 \mathrm{~Hz} ; \mathrm{H}=0.658 . \mathrm{Kp} 1=200, \mathrm{Ki} 1=200, \mathrm{Kp} 2=95.7, \mathrm{Ki} 2=66.6, \mathrm{Kp} 3=0.01, \mathrm{Ki} 3=0.01, \mathrm{Kp} 4=100$, Ki4=0.01, $\mathrm{Kp} 5=9.1551, \mathrm{Ki} 5=77.7758$.

\section{REFERENCES}

[1] A. J. Jeman A, M. S. Hannoon N, Hidayat N, et al. "Stability check of doubly fed induction generator (DFIG) micro grid power system," Bulletin of Electrical Engineering and Informatics, vol. 8 no. 2, pp. 367-374, June 2019.

[2] Shahzad Nazir M, Wu Q, Li M., "Symmetrical Short-Circuit Parameters Comparison of DFIG-WT," Int J Electr Comput Eng Syst 2017; vol. 8, no.2, pp. 77-83, 2017.

[3] S. Xiao, G. Yang and H. Zhou, "A LVRT control strategy based on flux tracking for DFIG-based wind power systems," 8th International Conference on Power Electronics-ECCE Asia, Jeju, 2011, pp. 76-82.

[4] Arindya R. "A Variable Speed Wind Generation System Based on Doubly Fed Induction Generator," Bulletin of Electrical Engineering and Informatics, vol. 2, no. 4, pp. 272-277, 2013.

[5] Zhou X, Tang Y, Shi J. "Enhancing LVRT Capability of DFIG-Based Wind Turbine Systems with SMES Series in the Rotor Side," Int J Rotating Mach 2017, pp. 1-8, 2017.

[6] Kenan Döşoğlu M. "A new approach for low voltage ride through capability in DFIG based wind farm," Int J Electr Power Energy Syst 2016, vol. 83, pp. 251-258.

[7] Ozsoy E. E., Golubovic E, Sabanovic A, et al. "A Novel Current Controller Scheme for Doubly Fed Induction Generators," Automatika 2015, vol. 56, pp. 186-195.

[8] J. Yang, J. E. Fletcher and J. O'Reilly, "A Series-Dynamic-Resistor-Based Converter Protection Scheme for Doubly-Fed Induction Generator During Various Fault Conditions," in IEEE Transactions on Energy Conversion, vol. 25, no. 2, pp. 422-432, June 2010.

[9] G. Pannell, B. Zahawi, D. J. Atkinson and P. Missailidis, "Evaluation of the Performance of a DC-Link Brake Chopper as a DFIG Low-Voltage Fault-Ride-Through Device," in IEEE Transactions on Energy Conversion, vol. 28, no. 3, pp. 535-542, Sept. 2013.

[10] N. Y. Abed, M. M. Kabsha and G. M. Abdlsalam, "Low Voltage Ride-Through protection techniques for DFIG wind generator," 2013 IEEE Power \& Energy Society General Meeting, Vancouver, BC, 2013, pp. 1-6.

[11] Boulahia A, Adel M, Benalla H. "Predictive Power Control of Grid and Rotor Side converters in Doubly Fed Induction Generators Based Wind Turbine," Bulletin of Electrical Engineering and Informatics2013, vol.2, no. 4, pp. 258-264.

[12] M. Y. Khamaira, A. M. Shiddiq Yunus and A. Abu-Siada, "Improvement of DFIG-based WECS performance using SMES unit," 2013 Australasian Universities Power Engineering Conference (AUPEC), Hobart, TAS, pp. 1-5, 2013.

[13] Iyasere E, Salah MH, Dawson DM, et al. "Robust nonlinear control strategy to maximize energy capture in a variable speed wind turbine with an internal induction generator," J Control Theory Appl 2012; vol. 10, pp. 184-194.

[14] Wang B, Qian Y, Zhang Y. "Robust nonlinear controller design of wind turbine with doubly fed induction generator by using Hamiltonian energy approach,"J Control Theory Appl 2013, vol. 11, pp. 282-287.

[15] Song H, Qu Y., "Energy-based modeling and control for grid-side converter of doubly fed wind generator," $J$ Control Theory Appl 2012, vol. 10, pp.435-440.

[16] Gayen P. K., Chatterjee D, "Goswami SK. An improved low-voltage ride-through performance of DFIG based wind plant using stator dy namic composite fault current limiter," ISA Trans 2016,vol. 62, pp. 333-348.

[17] Kavitha A, Suresh A V. "A Novel Inter Connection of DFIG with Grid in Separate Excitation SMES System with Fuzzy Logic Control," Bulletin of Electrical Engineering and Informatics, vol. 4, no. 1, pp. 43-52, 2015.

[18] W. Guo, L. Xiao, S. Dai, X. Xu, Y. Li and Y. Wang, "Evaluation of the Performance of BTFCLs for Enhancing LVRT Capability of DFIG," in IEEE Transactions on Power Electronics, vol. 30, no. 7, pp. 3623-3637, July 2015

[19] Zhang X, Cao X, Wang W, et al. "Fault Ride-Through Study of Wind Turbines," J Power Energy Eng 2013, vol. 01, pp 25-29. 
[20] Naderi S. B., Negnevitsky M, Jalilian A, et al. "Low voltage ride-through enhancement of DFIG-based wind turbine using DC link switchable resistive type fault current limiter," Int J Electr Power Energy Syst, 2017, vol. 86, pp. 104-119.

[21] A. O. Ibrahim, T. H. Nguyen, D. Lee and S. Kim, "A Fault Ride-Through Technique of DFIG Wind Turbine Systems Using Dynamic Voltage Restorers," in IEEE Transactions on Energy Conversion, vol. 26, no. 3, pp. 871-882, Sept. 2011.

[22] Döşoğlu M. K., "Enhancement of SDRU and RCC for low voltage ride through capability in DFIG based wind farm," Electr Eng, vol.99, pp.673-683.2017.

[23] Swain S, Ray P. K., "Short circuit fault analysis in a grid connected DFIG based wind energy system with active crowbar protection circuit for ridethrough capability and power quality improvement," Int J Electr Power Energy Syst 2017, vol. 84, pp. 64-75.

[24] N. W. Miller, J. J. Sanchez-Gasca, W. W. Price and R. W. Delmerico, "Dynamic modeling of GE 1.5 and 3.6 MW wind turbine-generators for stability simulations," 2003 IEEE Power Engineering Society General Meeting (IEEE Cat. No.03CH37491), Toronto, Ont, vol. 3, pp. 1977-1983, 2003

[25] Rafiee Z, Meyabadi AF. "Optimal design of power system stabiliser using a new cost function and PSO algorithm," Int J Power Energy Convers, vol. 3, pp. 253-264, 2012.

[26] Rafiee Z, Meyabadi AF, Heydari H. PSS "parameters values finding using SMVSDFT objective function and a new technique for multi-objective function in a multi-machine power system," Int J Power Energy Convers, vol. 6, no. 3, pp. 252-266, 2015.

\section{BIOGRAPHIES OF AUTHORS}

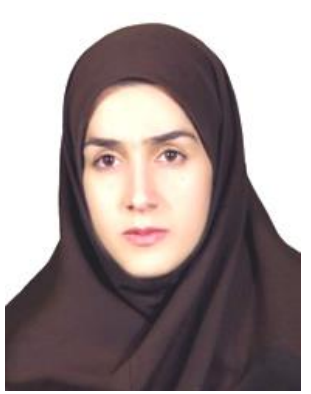

Zahra Rafiee, received her BS degree in Power Electricity Engineering from the Department of Electrical Engineering, Bu Ali Sina University, Hamadan Iran, in 2006 and an MS degree in Power Electricity Engineering from the Department of Electrical Engineering, Bu Ali Sina University, Hamadan Iran, in 2010. She studies $\mathrm{PhD}$ in Electrical Engineering in Shahid Beheshti University. Her research interests are in stability in power system, protection of network, optimization control algorithms, power system stabilizer and, distributed generation, application of neural network and fuzzy logic in electricity.

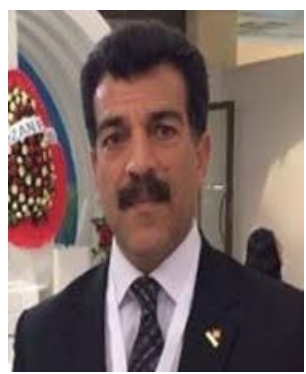

Mansour Rafiee, was born in 1967 in Iran. He works in Shahid Beheshti University as a member of the Academic Staff and currently he is the head of distributed generation research lab. Also he has been the Vice President of Meyar Tose'e Niroo-a leading Iranian company in developing, design and consultancy of renewable energy projects-since 2003.

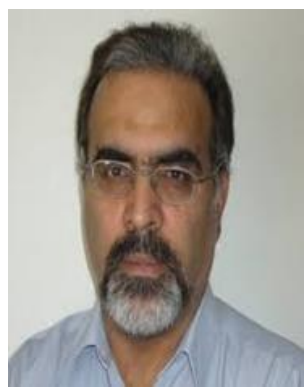

Mohammad Reza Aghamohammadi, was born in Iran on August 5, 1955. He received his BSC degree from Sharif University of Technology 1981, MSc degree from Manchester University (UMIST) in 1984 and his PhD from Tohoku University, Japan in 1994. He is an associate professor of the electrical engineering department and head of Iran Dynamic Research Center. His research interest includes application of intelligent techniques and non-model based approaches for dy namic security assessment and enhancement of power systems. 